Article

\title{
Prevalence and Associated Factors of Low Bone Mineral Density in the Femoral Neck and Total Hip in Axial Spondyloarthritis: Data from the CASTRO Cohort
}

\author{
Laura Bautista-Aguilar 1,2,3, Clementina López-Medina 1,2,3,*(D), Lourdes Ladehesa-Pineda 1,2,3, \\ María del Carmen Ábalos-Aguilera 1,2,3, Desirée Ruiz-Vilchez 1,2,3, Juan Luis Garrido-Castro ${ }^{3}$ (D), \\ Ignacio Gómez-García 1,2,3 (D), María Ángeles Puche-Larrubia 1,2,3, Asunción Salmoral-Chamizo 1,2, \\ Eduardo Collantes-Estévez ${ }^{1,2,3}$, Alejandro Escudero-Contreras $1,2,3,+\mathbb{D}$ and Pilar Font-Ugalde $1,2,3,+(\mathbb{D}$
}

1 Rheumatology Department, Reina Sofia University Hospital, 14004 Cordoba, Spain; laurabautistaag@gmail.com (L.B.-A.); lourdesladehesapineda@gmail.com (L.L.-P.); mc.abalos@outlook.com (M.d.C.Á.-A.); desiree.ruiz@imibic.org (D.R.-V.); ignaciogomgar@gmail.com (I.G.-G.); mangeles.puche@gmail.com (M.Á.P.-L.); asuncionsalmoral61@gmail.com (A.S.-C.); educollantes@yahoo.es (E.C.-E.); alexcudero2@gmail.com (A.E.-C.); fougp@hotmail.com (P.F.-U.)

2 GC05 Group, Maimonides Institute of Biomedical Research of Cordoba, 14004 Cordoba, Spain

check for updates

Citation: Bautista-Aguilar, L.; López-Medina, C.; Ladehesa-Pineda, L.; Ábalos-Aguilera, M.d.C.;

Ruiz-Vilchez, D.; Garrido-Castro, J.L.; Gómez-García, I.; Puche-Larrubia, M.Á.; Salmoral-Chamizo, A.; Collantes-Estévez, E.; et al. Prevalence and Associated Factors of Low Bone Mineral Density in the Femoral Neck and Total Hip in Axial Spondyloarthritis: Data from the CASTRO Cohort. J. Clin. Med. 2021, 10, 2664. https://doi.org/10.3390/ jcm10122664

Academic Editor: Vincent Goeb

Received: 14 May 2021

Accepted: 14 June 2021

Published: 17 June 2021

Publisher's Note: MDPI stays neutral with regard to jurisdictional claims in published maps and institutional affiliations.

Copyright: (c) 2021 by the authors. Licensee MDPI, Basel, Switzerland This article is an open access article distributed under the terms and conditions of the Creative Commons Attribution (CC BY) license (https:// creativecommons.org/licenses/by/ $4.0 /$ )
3 Medical and Surgical Sciences Department, University of Cordoba, 14004 Cordoba, Spain; cc0juanl@uco.es

* Correspondence: clementinalopezmedina@gmail.com

$\dagger \quad$ These authors contributed equally.

Abstract: Studies on osteoporosis in axial spondyloarthritis (axSpA) have focused on the lumbar segment, and few studies have assessed bone mineral density (BMD) in the hip and femoral neck in these patients. The aim of this study was to evaluate the prevalence of low BMD and osteopenia in the total hip or femoral neck and the factors associated with these conditions in axSpA patients. This was a single-centre, observational, cross-sectional study among consecutive patients with axSpA according to the ASAS criteria from the CASTRO registry. All patients underwent total hip and femoral neck DXA BMD measurements. Low BMD was defined as a Z-score less than -1 , and osteopenia was defined as a T-score less than -1 . Multivariate logistic and generalised linear regressions were used to evaluate factors independently associated with low BMD and osteopenia in the hip or femoral neck and those associated with variability in BMD, respectively. A total of 117 patients were included, among which $30.8 \%$ were female and the mean age was 45 years. A total of $36.0 \%$ of patients had low BMD (28.1\% in the total hip and $27.4 \%$ in the femoral neck), and $56.0 \%$ of patients had osteopenia ( $44.7 \%$ in the total hip and $53.8 \%$ in the femoral neck). A multivariate logistic regression showed that age, radiographic sacroiliitis and ASAS-HI were independently associated with low BMD in the total hip or femoral neck. Factors that were independently associated with osteopenia were Body Mass Index, disease duration, radiographic sacroiliitis and ASAS-HI. In conclusion, $36 \%$ of the patients with axSpA had low BMD in the total hip or femoral neck. A younger age and radiographic sacroiliitis were the most important factors associated with decreased BMD.

Keywords: axial spondyloarthritis; bone mineral density; osteopenia

\section{Introduction}

Spondyloarthritis (SpA) is a heterogeneous group of rheumatic diseases that involve the axial skeleton and peripheral joints [1]. Patients with predominantly axial symptoms are generally classified as having axial SpA (axSpA), and those with predominantly peripheral symptoms are typically diagnosed with peripheral SpA (pSpA) [2]. Axial SpA is characterised by inflammatory back pain, vertebral fusion in some cases and restricted spinal mobility. During the clinical course of the disease, patients with axSpA may also suffer from other clinical disorders, known as comorbidities. Osteoporosis is the most frequent comorbidity in these patients, with a global prevalence of $13.4 \%$ [3]. 
Bone remodelling is altered in axSpA patients, as inflammation causes osteoproliferation in cortical areas of the vertebrae and the loss of trabecular bone in vertebral bodies. As a consequence, low bone mass and biomechanical alteration of the spine produce an increased risk of vertebral fractures [4,5]. SpA has been associated with bone loss not only in the spine but also in the hip [6]. Factors associated with a decrease in bone mineral density (BMD) in these patients are systemic inflammation, which is evaluated by C-reactive protein (CRP) levels or the erythrocyte sedimentation rate [4], and local inflammation, which is diagnosed by bone marrow oedema on magnetic resonance imaging (MRI) of the spine [5]. In addition, impaired back mobility and spinal ankylosis have been associated with low BMD [7].

Most studies evaluating BMD in SpA have focused on the lumbar spine. However, lumbar BMD in axSpA patients can be overestimated due to the presence of syndesmophytes or other structural lesions, such as ankylosis of the posterior ligament and periosteal bone formation [8]. In addition, inflammation in these patients has a direct effect on the trabecular bone of the vertebrae but not on the cortical bone. Consequently, lumbar dualenergy X-ray absorptiometry (DXA) has several limitations in the evaluation of BMD [9]. For this reason, the European League Against Rheumatism (EULAR) taskforce provided recommendations on the evaluation of BMD in SpA patients. According to these guidelines, in patients with syndesmophytes in the lumbar spine on conventional radiography, BMD should be assessed using hip DXA supplemented with either DXA of the lateral projection of the spine or quantitative computed tomography (QCT) of the spine [10]. However, despite these recommendations, the majority of studies evaluating osteoporosis in axSpA patients have focused on the lumbar segment, and very few published studies have evaluated BMD in the hip and femoral neck in these patients.

Therefore, we conducted this study with the aim of assessing the prevalence of low BMD (i.e., Z-score less than -1) and osteopenia (i.e., T-score less than -1) and the factors associated with these conditions (in both the femoral neck and total hip) in axSpA patients.

\section{Materials and Methods}

\subsection{Study Population}

This was a single-centre, observational, cross-sectional study of 117 consecutive patients with axSpA according to the Assessment of Spondylitis International Society (ASAS) criteria from the Córdoba Axial Spondyloarthritis Task Force, Registry and Outcomes (CASTRO). The CASTRO registry includes 182 axSpA patients; however, 65 patients were excluded from this specific analysis for several reasons. Excluded patients were those who were (a) missing data for DXA of the total hip and femoral neck $(n=55)$; (b) receiving treatment with drugs that could interfere with bone metabolism (bisphosphonates, strontium ranelate, selective oestrogenic receptor modulators, calcitonin, hormone therapy, denosumab or teriparatide) $(n=4)$; (c) suffering from metabolic bone diseases (hyperthyroidism, hypercortisolism, hyperparathyroidism, malabsorption syndrome, Paget's disease or malignant tumours) $(n=1)$; (d) receiving treatment that could cause osteoporosis (corticosteroids, acenocoumarol, heparin or anticonvulsants) $(n=2)$; and (e) on biological disease-modifying drugs (bDMARDs) $(n=3)$. This study was approved by the Ethics Committee at the Reina Sofia University Hospital (protocol code PI-0139-2017), and all the patients signed informed consent forms for inclusion.

\subsection{Data Collection}

Data were collected during medical visits to the Rheumatology Unit of the Reina Sofia University Hospital in Cordoba, Spain. The following data were collected:

- Demographic data: Age, sex, Body Mass Index (BMI) and smoking status were obtained.

- Clinical data: Disease duration, diagnostic delay, and previous history of arthritis, enthesitis, dactylitis, uveitis, psoriasis, inflammatory bowel disease (IBD) and uveitis were identified. Radiographs of the cervical spine, lumbar spine and sacroiliac joints 
were obtained at the time of the BMD assessment. Lateral views of the cervical and lumbar spine were scored according to the modified Stoke Ankylosing Spondylitis Spinal Score (mSASSS index) [11]. Sacroiliitis was scored according to the modified New York criteria [12]. Sacroiliitis and mSASSS were scored by two trained rheumatologists who were blinded to patient characteristics. The intraclass correlation coefficient score for agreement between the readers was 0.99 for the total mSASSS, and the mean value of the two readers was used. The kappa score for agreement between the two readers for the modified New York criteria was 0.76 . In cases of disagreement, the evaluation from the senior reader was used.

- $\quad$ Blood test: HLA-B27 antigen and CRP levels were reported.

- Treatments: Data on the use of non-steroidal anti-inflammatory drugs (NSAIDs), corticosteroid intake and vitamin D supplementation were collected.

- Disease activity and function: The self-administered questionnaires from the Bath Ankylosing Spondylitis Disease Activity Index (BASDAI) [13], Bath Ankylosing Spondylitis Functional Index (BASFI) [14] and ASAS-endorsed Disease Activity Score (ASDAS) [15] were used. In addition, CRP levels (mg/L) were recorded retrospectively once, twice or three times during the 5 years prior to the study and at the time of the study to evaluate the persistence of inflammation. A patient was considered to have persistent inflammation if they had increased CRP levels ( $>10 \mathrm{mg} / \mathrm{L})$ in at least $50 \%$ of the measurements in the previous 5 years.

- $\quad$ Bone mineral density (BMD): All participants underwent DXA BMD measurement of the total hip and femoral neck using a dual X-ray absorptiometry (DXA) LUNAR DPX 8548 BX-1 L densitometer (coefficient of variation $<1 \%$ ). All measurements were made by the same operator. World Health Organization (WHO) criteria were used for the diagnosis of osteopenia (i.e., T-score less than -1 ), osteoporosis (i.e., T-score less than -2.5), low BMD (Z-score less than -1$)$ and very low BMD (Z-score less than -2) [16].

- $\quad$ Spinal mobility was studied using both the total University of Cordoba Ankylosing Spondylitis Metrology Index (UCOASMI) and the individual items of the UCOASMI, which is a composite index based on an automated system that generates a cervical and vertebral mobility score from serial kinematic measurements [17-19]. Among other measures, it evaluates lumbar anterior flexion, lateral flexion and rotation in grades. The total UCOASMI score ranges from 0 to 10 (from better to worse mobility). The motion video-capture system consists of 11 reflective markers placed in anatomical points, four cameras and specific software (UCOTrack). Markers are attached in less than $2 \mathrm{~min}$. The patient must then perform specific movements, such as flexion, extension and rotation. The software interprets the images and generates summary measures that are included in the index: cervical frontal flexion, cervical rotation, frontal spinal flexion, shoulder-hip lateral angle and trunk rotation.

\subsection{Statistical Analysis}

A descriptive analysis of the variables was conducted. Absolute and relative frequencies were calculated for the qualitative variables, and the mean and standard deviation (SD) were determined for continuous values.

Univariate and multivariate logistic regression models using a backward stepwise procedure were conducted to evaluate sociodemographic, clinical and disease activity factors associated with low BMD (i.e., Z-score less than -1) in the total hip or femoral neck. Variables with a $p$-value $<0.20$ in the univariate analysis were subjected to a multivariate analysis, and the degree of association was expressed as the odds ratio (OR) and 95\% confidence interval. Interaction and confounding factors were tested. The same analysis was conducted to evaluate factors associated with osteopenia (i.e., T-score less than -1) in the total hip or femoral neck.

Finally, to determine the factors independently associated with BMD, two separate univariate and multivariate generalised linear models (one for the femoral neck and a 
second one for the total hip) were conducted. Multicollinearity, homogeneity of variance and normality of residuals were tested.

All comparisons were bilateral, and $p<0.05$ was considered a significant result. Data were analysed using R Studio 1.3.1073 ( ) (www.rstudio.com, accessed on 14 April 2021).

\section{Results}

Among the 117 patients included, $30.8 \%$ were female, and the mean age was 45 years old. A total of $36.0 \%$ of patients had low BMD (28.1\% in the total hip and $27.4 \%$ in the femoral neck). In addition, a total of $56.0 \%$ of patients had osteopenia ( $44.7 \%$ in the total hip and $53.8 \%$ in the femoral neck). The demographic and clinical characteristics of the patients are summarised in Table 1.

Table 1. Descriptive data of the included population.

\begin{tabular}{|c|c|}
\hline & $\begin{array}{c}\text { Total } \\
n=117\end{array}$ \\
\hline Sex (female) & $36(30.8 \%)$ \\
\hline Age, mean (SD) & $45.4(12.1)$ \\
\hline BMI, mean (SD) & $26.6(4.1)$ \\
\hline Caucasian ethnicity & $117(100 \%)$ \\
\hline Current smoking & $45(38.5 \%)$ \\
\hline Disease duration, mean (SD) & $19.2(13.9)$ \\
\hline Diagnosis delay, mean (SD) & $5.2(6.3)$ \\
\hline Radiographic sacroiliitis & $94 / 116(81.0 \%)$ \\
\hline HLA-B27 positive & $91 / 115(79.1 \%)$ \\
\hline Arthritis (ever) & $25(21.4 \%)$ \\
\hline Enthesitis (ever) & $15 / 113(13.3 \%)$ \\
\hline Dactylitis (ever) & $8(6.8 \%)$ \\
\hline Psoriasis & $14(12.0 \%)$ \\
\hline Uveitis (ever) & $24(20.5 \%)$ \\
\hline IBD & $4 / 112(3.6 \%)$ \\
\hline CRP, mean (SD) & $6.5(10.8)$ \\
\hline ASDAS-CRP, mean (SD) & $2.4(0.9)$ \\
\hline Persistent CRP & $43(36.8 \%)$ \\
\hline NSAIDs (ever) & $106 / 115(92.2 \%)$ \\
\hline Vitamin D supplementation (ever) & $6(5.1 \%)$ \\
\hline UCOASMI, mean (SD) & $4.2(1.7)$ \\
\hline Lumbar flexion, mean (SD) & $58.7(22.0)$ \\
\hline Total mSASSS, mean (SD) & $13.9(16.3)$ \\
\hline ASAS-HI, mean (SD) & $4.8(4.0)$ \\
\hline BASDAI, mean (SD) & $3.6(2.1)$ \\
\hline BASFI, mean (SD) & $3.1(2.6)$ \\
\hline Total hip BMD $\left(\mathrm{g} / \mathrm{cm}^{2}\right)$ & $0.98(0.18)$ \\
\hline Femoral neck BMD $\left(\mathrm{g} / \mathrm{cm}^{2}\right)$ & $0.92(0.15)$ \\
\hline Lumbar BMD $\left(\mathrm{g} / \mathrm{cm}^{2}\right)$ & $1.11(0.19)$ \\
\hline Total hip BMD T-score less than -1 (osteopenia) & $51 / 114(44.7 \%)$ \\
\hline Total hip BMD T-score less than -2.5 (osteoporosis) & $2 / 114(1.8 \%)$ \\
\hline Total hip BMD Z-score less than -1 (low BMD) & $32 / 114(28.1 \%)$ \\
\hline Total hip BMD Z-score less than -2 (very low BMD) & $6 / 114(5.3 \%)$ \\
\hline Femoral neck BMD T-score less than -1 (osteopenia) & $63(53.8 \%)$ \\
\hline Femoral neck BMD T-score less than -2.5 (osteoporosis) & $4(3.4 \%)$ \\
\hline Femoral neck BMD Z-score less than -1 (low BMD) & $32(27.4 \%)$ \\
\hline Femoral neck BMD Z-score less than -2 (very low BMD) & $4(3.4 \%)$ \\
\hline Total hip or femoral neck T-score less than -1 (osteopenia) & $65 / 116(56.0 \%)$ \\
\hline Total hip or femoral neck Z-score less than -1 (low BMD) & $41 / 114(36.0 \%)$ \\
\hline Lumbar BMD T-score less than -1 (osteopenia) & $57(48.7 \%)$ \\
\hline Lumbar BMD T-score less than -2.5 (osteoporosis) & $11(9.4 \%)$ \\
\hline Lumbar BMD Z-score less than -1 (low BMD) & $55(47.0 \%)$ \\
\hline Lumbar BMD Z-score less than -2 (very low BMD) & $18(15.4 \%)$ \\
\hline Current vitamin D level (ng/mL), mean (SD) & $17.1(9.8)$ \\
\hline
\end{tabular}

ASAS-HI: ASAS Health Index; ASDAS: ASAS-endorsed Disease Activity Score; BASDAI: Bath Ankylosing Spondylitis Disease Activity Index; BASFI: Bath Ankylosing Spondylitis Functional Index; BMD: bone mineral density; BMI: Body Mass Index; CRP: C-reactive protein; IBD: inflammatory bowel disease; mSASSS: modified Stoke Ankylosing Spondylitis Spinal Score; NSAIDs: non-steroidal anti-inflammatory drugs; SD: standard deviation; UCOASMI: University of Cordoba Ankylosing Spondylitis Metrology Index. 


\subsection{Factors Associated with Low BMD in the Total Hip or Femoral Neck}

Univariate logistic regression (Table 2) showed no significant association between low $\mathrm{BMD}$ in the total hip or femoral neck and the other covariates. However, the multivariate logistic regression (Figure 1A) showed that age (OR 0.96, 95\% CI 0.93-0.99), radiographic sacroiliitis (OR 4.26, 95\% CI 1.33-16.34) and higher ASAS-HI scores (OR 1.14, 95\% CI $1.02-1.28)$ were independently associated with low BMD of the total hip or femoral neck.

Table 2. Univariate logistic regression to evaluate the factors associated with low BMD in the total hip or femoral neck.

\begin{tabular}{ccccc}
\hline & Yes $\mathbf{4 1}$ & Low BMD in the Total Hip or Femoral Neck \\
$\mathbf{N o = 7 3}$ & $\boldsymbol{n} \mathbf{( \% )}$ & OR (95\% CI) & $\boldsymbol{p}$-Value \\
\hline Age, mean (SD) & $\mathbf{n} \mathbf{( \% )}$ & $46.2(11.9)$ & $0.98(0.94-1.01)$ & 0.168 \\
Sex (female) & $43.0(12.2)$ & $22(30.1 \%)$ & $0.96(0.41-2.20)$ & 0.923 \\
BMI, mean (SD) & $12(29.3 \%)$ & $26.9(3.9)$ & $0.96(0.87-1.06)$ & 0.423 \\
Current smoking & $26.2(4.7)$ & $23(31.5 \%)$ & $2.07(0.94-4.58)$ & 0.070 \\
Disease duration, mean (SD) & $20(48.8 \%)$ & $19.3(14.2)$ & $0.99(0.97-1.03)$ & 0.882 \\
HLA-B27 & $18.9(13.7)$ & $61(83.6 \%)$ & $0.50(0.20-1.28)$ & 0.146 \\
Radiographic sacroiliitis & $28 / 39(71.8 \%)$ & $55 / 72(76.4 \%)$ & $2.23(0.80-7.25)$ & 0.147 \\
Psoriasis & $36(87.8 \%)$ & $9(12.3 \%)$ & $0.99(0.29-3.09)$ & 0.983 \\
IBD & $5(12.2 \%)$ & $1 / 71(1.4 \%)$ & $6.00(0.74-123.72)$ & 0.127 \\
ASDAS-CRP, mean (SD) & $3 / 38(7.9 \%)$ & $2.3(0.9)$ & $1.23(0.82-1.85)$ & 0.318 \\
Persistent CRP & $2.5(1.0)$ & $25(34.2 \%)$ & $1.23(0.55-2.71)$ & $0.99(0.97-1.02)$ \\
Total mSASSS, mean (SD) & $16(39.0 \%)$ & $14.1(16.6)$ & $0.95(0.74-1.21)$ & 0.780 \\
UCOASMI, mean (SD) & $13.2(16.3)$ & $4.2(1.8)$ & $0.99(0.98-1.01)$ & 0.695 \\
Lumbar flexion, mean (SD) & $4.1(1.5)$ & $59.6(22.7)$ & $0.67(0.17-2.86)$ & 0.656 \\
NSAIDs (ever) & $57.5(21.8)$ & $67 / 72(93.1 \%)$ & $1.07(0.97-1.19)$ & 0.571 \\
ASAS-HI, mean (SD) & $36 / 40(90.0 \%)$ & $4.2(3.8)$ & $1.09(0.91-1.30$ & 0.160 \\
BASDAI, mean (SD) & $5.4(4.2)$ & $3.4(2.0)$ & $1.13(0.98-1.32)$ & 0.352 \\
BASFI, mean (SD) & $3.8(2.4)$ & $2.7(2.5)$ & 0.105 \\
\hline
\end{tabular}

ASAS-HI: ASAS Health Index; ASDAS: ASAS-endorsed Disease Activity Score; BASDAI: Bath Ankylosing Spondylitis Disease Activity Index; BASFI: Bath Ankylosing Spondylitis Functional Index; BMD: bone mineral density; BMI: Body Mass Index; CRP: C-reactive protein; IBD: inflammatory bowel disease; mSASSS: modified Stoke Ankylosing Spondylitis Spinal Score; NSAIDs: non-steroidal anti-inflammatory drugs; SD: standard deviation; UCOASMI: University of Cordoba Ankylosing Spondylitis Metrology Index.

A

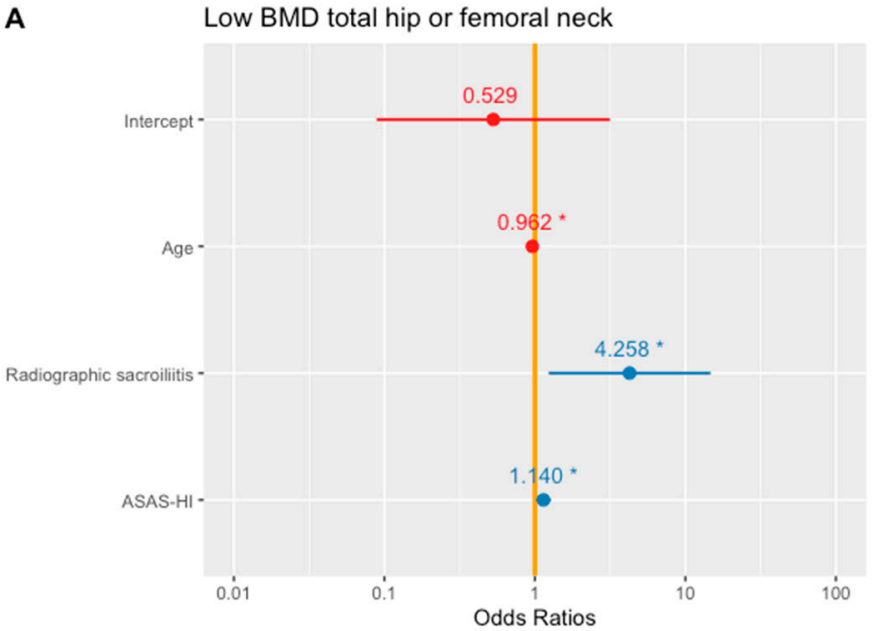

B

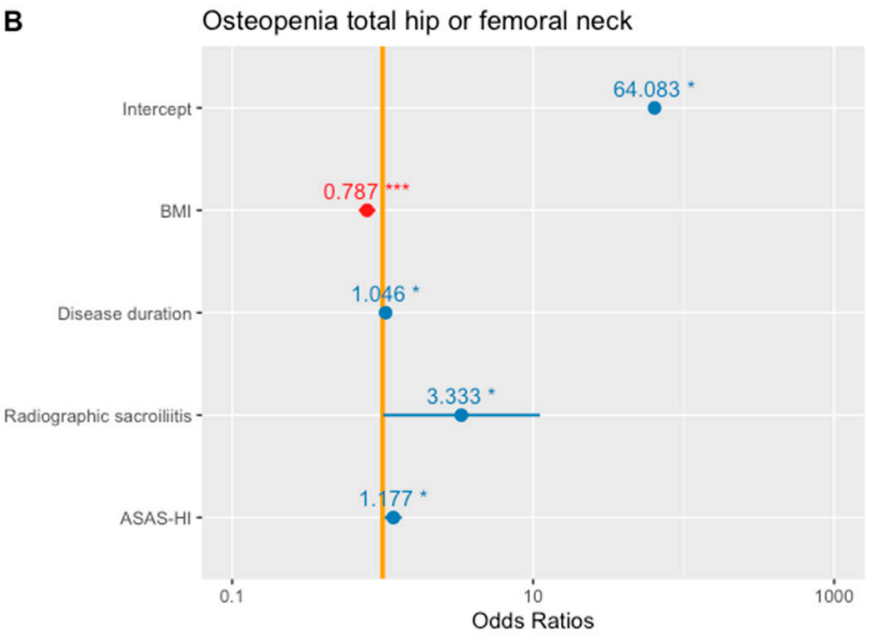

Figure 1. Multivariate logistic regression to evaluate the factors associated with low BMD (A) and osteopenia (B) in the total hip or femoral neck. ASAS-HI: ASAS Health Index; BMI: Body Mass Index. ${ }^{*}, p$-value $<0.05 ;{ }^{* * *}, p$-value $<0.001$. 


\subsection{Factors Associated with Osteopenia in the Total Hip or Femoral Neck}

The univariate logistic regression (Table 3) showed a significant association between osteopenia in the total hip or femoral neck and age (OR 1.03, 95\% CI 1.01-1.07), BMI (OR $0.86,95 \%$ CI 0.77-0.94), disease duration (OR 1.04, 95\% CI 1.01-1.07), ASAS-HI (OR 1.10, 95\% CI 1.00-1.23) and BASFI (OR 1.19, 95\% CI 1.03-1.40). In addition, the multivariate logistic regression (Figure 1B) showed that BMI (OR 0.79, 95\% CI 0.69-0.89), disease duration (OR 1.05, 95\% CI 1.01-1.09), radiographic sacroiliitis (OR 3.33, 95\% CI 1.03-11.81) and higher ASAS-HI scores (OR 1.18, 95\% CI 1.04-1.35) were independently associated with osteopenia in the total hip or femoral neck.

Table 3. Univariate logistic regression to evaluate the factors associated with osteopenia in the total hip or femoral neck.

\begin{tabular}{|c|c|c|c|c|}
\hline & \multicolumn{4}{|c|}{ Osteopenia in the Total Hip or Femoral Neck } \\
\hline & $\begin{array}{c}\text { Yes }=65 \\
n(\%)\end{array}$ & $\begin{array}{c}\text { No }=51 \\
n(\%)\end{array}$ & OR $(95 \%$ CI $)$ & $p$-Value \\
\hline Age, mean (SD) & $47.6(12.8)$ & $42.5(10.5)$ & $1.03(1.01-1.07)$ & 0.026 \\
\hline Sex (female) & $20(30.7 \%)$ & $15(29.4 \%)$ & $1.07(0.48-2.4)$ & 0.874 \\
\hline BMI, mean (SD) & $25.6(3.8)$ & $28.0(4.3)$ & $0.86(0.77-0.94)$ & 0.003 \\
\hline Current smoking & $26(40.0 \%)$ & $18(35.3 \%)$ & $1.22(0.57-2.63)$ & 0.604 \\
\hline Disease duration, mean (SD) & $22.1(15.2)$ & $15.4(11.0)$ & $1.04(1.01-1.07)$ & 0.013 \\
\hline HLA-B27 & $48 / 63(76.2 \%)$ & $42(82.4 \%)$ & $0.69(0.26-1.70)$ & 0.424 \\
\hline Radiographic sacroiliitis & $56(86.2 \%)$ & $37 / 50(74.0 \%)$ & $2.19(0.86-5.80)$ & 0.105 \\
\hline Psoriasis & $7(10.8 \%)$ & $7(13.7 \%)$ & $0.76(0.24-2.37)$ & 0.628 \\
\hline IBD & $3 / 61(4.9 \%)$ & $1 / 50(2.0 \%)$ & $2.53(0.31-52.13)$ & 0.427 \\
\hline ASDAS-CRP, mean (SD) & $2.5(1.0)$ & $2.3(0.9)$ & $1.21(0.82-1.81)$ & 0.346 \\
\hline Persistent CRP & $24(36.9 \%)$ & $19(37.3 \%)$ & $0.99(0.46-2.11)$ & 0.971 \\
\hline Total mSASSS, mean (SD) & $14.8(16.7)$ & $12.4(15.9)$ & $1.01(0.99-1.04)$ & 0.434 \\
\hline UCOASMI, mean (SD) & $4.3(1.7)$ & $4.1(1.7)$ & $1.06(0.84-1.35)$ & 0.621 \\
\hline Lumbar flexion, mean (SD) & $54.8(20.4)$ & $63.4(23.4)$ & $0.98(0.96-1.00)$ & 0.057 \\
\hline NSAIDs (ever) & $59 / 63(93.7 \%)$ & $46 / 51(90.2 \%)$ & $1.60(0.40-6.80)$ & 0.500 \\
\hline ASAS-HI, mean (SD) & $5.4(4.1)$ & $3.9(3.7)$ & $1.10(1.00-1.23)$ & 0.047 \\
\hline BASDAI, mean (SD) & $3.7(2.2)$ & $3.4(2.1)$ & $1.08(0.91-1.29)$ & 0.369 \\
\hline BASFI, mean (SD) & $3.6(2.6)$ & $2.5(2.4)$ & $1.19(1.03-1.40)$ & 0.024 \\
\hline
\end{tabular}

ASAS-HI: ASAS Health Index; ASDAS: ASAS-endorsed Disease Activity Score; BASDAI: Bath Ankylosing Spondylitis Disease Activity Index; BASFI: Bath Ankylosing Spondylitis Functional Index; BMD: bone mineral density; BMI: Body Mass Index; CRP: C-reactive protein; IBD: inflammatory bowel disease; mSASSS: modified Stoke Ankylosing Spondylitis Spinal Score; NSAIDs: non-steroidal anti-inflammatory drugs; SD: standard deviation; UCOASMI: University of Cordoba Ankylosing Spondylitis Metrology Index.

\subsection{Factors Associated with Total Hip BMD}

A univariate generalised linear regression analysis was performed to determine factors associated with the total hip BMD in axSpA patients (Table 4), and the results showed no significant effect of age, BMI, disease duration, HLA B-27, UCOASMI, mSASSS or persistent CRP elevation. However, significant associations were found between the total hip BMD and female sex $(\beta-0.082,95 \% \mathrm{CI}-0.154$ to -0.011$)$, radiographic sacroiliitis $(\beta-0.097,95 \%$ CI -0.180 to -0.014$)$, psoriasis $(\beta 0.111,95 \%$ CI $0.012-0.211)$, lumbar flexion $(\beta 0.002,95 \%$ CI $0.000-0.004)$, previous or current intake of NSAIDs $(\beta-0.156,95 \%$ CI -0.277 to -0.034$)$, ASAS-HI ( $\beta-0.014,95 \% \mathrm{CI}-0.022$ to -0.005$)$, BASDAI ( $\beta-0.016,95 \% \mathrm{CI}-0.031$ to 0.001$)$ and BASFI $(\beta-0.018,95 \% \mathrm{CI}-0.031$ to -0.006$)$. A multivariate generalised regression analysis (Figure 2A) showed that BMI, disease duration, radiographic sacroiliitis, previous or current use of NSAIDs and ASAS-HI were independently associated with total hip BMD. 
Table 4. Univariate generalised linear regression to evaluate the factors associated with total hip bone mineral density.

\begin{tabular}{ccc}
\hline & Beta Coefficient (95\% CI) & $p$-Value \\
\hline Age & $-0.003(-0.005$ to 0.000$)$ & 0.067 \\
Sex (female) & $-0.082(-0.154$ to -0.011$)$ & 0.026 \\
BMI & $0.008(-0.001$ to 0.016$)$ & 0.055 \\
Current smoking & $-0.013(-0.081$ to 0.056$)$ & 0.722 \\
Disease duration & $-0.002(-0.004$ to 0.001$)$ & 0.056 \\
HLA-B27 & $0.013(-0.071$ to 0.097$)$ & 0.761 \\
Radiographic sacroiliitis & $-0.097(-0.180$ to -0.014$)$ & 0.024 \\
Psoriasis & $0.111(0.012-0.211)$ & 0.031 \\
IBD & $-0.095(-0.277$ to 0.087$)$ & 0.308 \\
ASDAS-CRP & $-0.034(-0.069$ to 0.001$)$ & 0.056 \\
Persistent CRP & $-0.001(-0.069$ to 0.071$)$ & 0.976 \\
Total mSASSS & $-0.001(-0.003$ to 0.001$)$ & 0.357 \\
UCOASMI & $-0.011(-0.033$ to 0.010$)$ & 0.308 \\
Lumbar flexion & $0.002(0.000-0.004)$ & 0.025 \\
NSAIDs (ever) & $-0.156(-0.277$ to -0.034$)$ & 0.013 \\
ASAS-HI & $-0.014(-0.022$ to -0.005$)$ & 0.002 \\
BASDAI & $-0.016(-0.031$ to 0.001$)$ & 0.046 \\
BASFI & $-0.018(-0.031$ to -0.006$)$ & 0.005 \\
\hline ASAS-HI: ASAS Health Index; ASDAS: ASAS-endorsed Disease Activity Score; BASDAI: Bath Ankylosing \\
Spondylitis Disease Activity Index; BASFI: Bath Ankylosing Spondylitis Functional Index; BMD: bone mineral \\
density; BMI: Body Mass Index; CRP: C-reactive protein; IBD: inflammatory bowel disease; mSASSS: modified \\
Stoke Ankylosing Spondylitis Spinal Score; NSAIDs: non-steroidal anti-inflammatory drugs; SD: standard \\
deviation; UCOASMI: University of Cordoba Ankylosing Spondylitis Metrology Index.
\end{tabular}

A

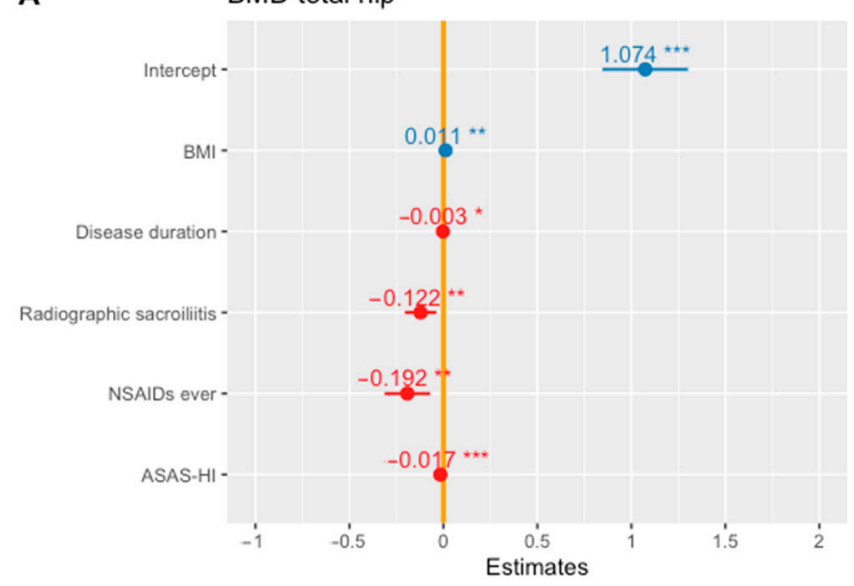

B $\quad$ BMD femoral neck

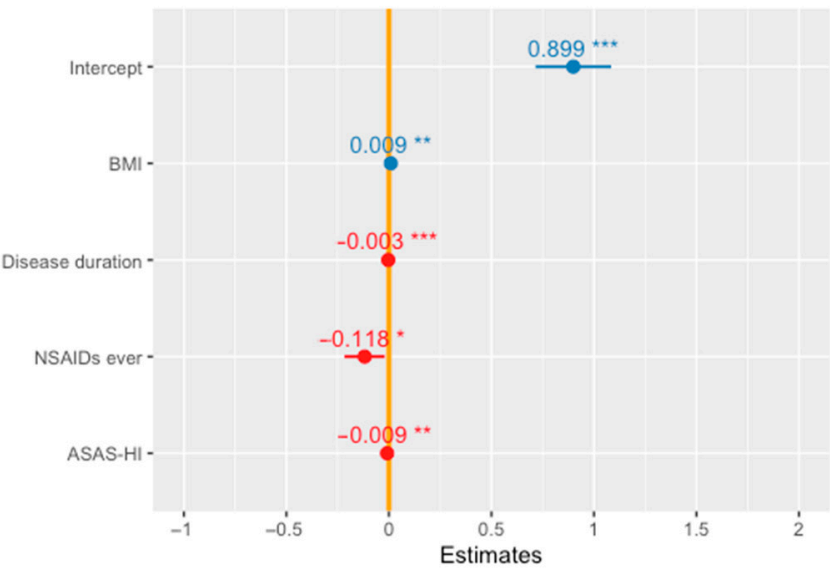

Figure 2. Multivariate generalised linear regressions to evaluate factors associated with bone mineral density in the total hip (A) and femoral neck (B). ASAS-HI: ASAS Health Index; BMI: Body Mass Index; NSAIDs: Non-steroidal anti-inflammatory drugs. ${ }^{*}, p$-value $<0.05 ;{ }^{* *}, p$-value $<0.01 ;{ }^{* *}, p$-value $<0.001$.

\subsection{Factors Associated with Femoral Neck BMD}

The univariate generalised linear regression analysis (Table 5 ) revealed associations between the femoral neck BMD and age $(\beta-0.004,95 \% \mathrm{CI}-0.006$ to -0.001$)$, female sex $(\beta$ $-0.063,95 \% \mathrm{CI}-0.120$ to -0.006$)$, disease duration $(\beta-0.003,95 \% \mathrm{CI}-0.005$ to -0.001$)$, lumbar flexion $(\beta 0.001,95 \%$ CI 0.000 to 0.002$)$, ASAS-HI $(\beta-0.010,95 \% \mathrm{CI}-0.017$ to $-0.003)$ and BASFI $(\beta-0.016,95 \%$ CI -0.026 to -0.006$)$.

The multivariate generalised linear regression analysis showed that BMI, disease duration, NSAID use and ASAS-HI were independently associated with femoral neck BMD (Figure 2B). 
Table 5. Univariate generalised linear regression to evaluate factors associated with femoral neck bone mineral density.

\begin{tabular}{ccc}
\hline & Beta Coefficient $\mathbf{9 5 \%}$ CI) & $p$-Value \\
\hline Age & $-0.004(-0.006$ to -0.001$)$ & 0.002 \\
Sex (female) & $-0.063(-0.120$ to -0.006$)$ & 0.033 \\
BMI & $0.006(-0.001$ to 0.012$)$ & 0.052 \\
Current smoking & $-0.001(-0.057$ to 0.054$)$ & 0.960 \\
Disease duration & $-0.003(-0.005$ to -0.001$)$ & 0.006 \\
HLA-B27 & $0.008(-0.060$ to 0.075$)$ & 0.820 \\
Radiographic sacroiliitis & $-0.056(-0.125$ to 0.013$)$ & 0.113 \\
Psoriasis & $0.030(-0.053$ to 0.113$)$ & 0.479 \\
IBD & $-0.085(-0.233$ to 0.064$)$ & 0.265 \\
ASDAS-CRP & $-0.022(-0.051$ to 0.006$)$ & 0.129 \\
Persistent CRP & $-0.009(-0.065$ to 0.047$)$ & 0.746 \\
Total mSASSS & $-0.001(-0.002$ to 0.001$)$ & 0.498 \\
UCOASMI & $-0.007(-0.025$ to 0.010$)$ & 0.399 \\
Lumbar flexion & $0.001(0.000$ to 0.002$)$ & 0.050 \\
NSAIDs (ever) & $-0.068(-0.169$ to 0.032$)$ & 0.187 \\
ASAS-HI & $-0.010(-0.017$ to -0.003$)$ & 0.004 \\
BASDAI & $-0.012(-0.025$ to 0.001$)$ & 0.061 \\
BASFI & $-0.016(-0.026$ to -0.006$)$ & 0.002 \\
\hline
\end{tabular}

ASAS-HI: ASAS Health Index; ASDAS: ASAS-endorsed Disease Activity Score; BASDAI: Bath Ankylosing Spondylitis Disease Activity Index; BASFI: Bath Ankylosing Spondylitis Functional Index; BMD: bone mineral density; BMI: Body Mass Index; CRP: C-reactive protein; IBD: inflammatory bowel disease; mSASSS: modified Stoke Ankylosing Spondylitis Spinal Score; NSAIDs: non-steroidal anti-inflammatory drugs; SD: standard deviation; UCOASMI: University of Cordoba Ankylosing Spondylitis Metrology Index.

\section{Discussion}

Our study showed that $36.0 \%$ of patients with axSpA had low BMD $(28.1 \%$ in the total hip and $27.4 \%$ in the femoral neck), and a total of $56.0 \%$ of patients had osteopenia ( $44.7 \%$ in the total hip and $53.8 \%$ in the femoral neck). The prevalence of low BMD in our population is similar to that published in the scientific literature $[6,7,20,21]$. However, it should be noted that lumbar DEXA was not considered in this study due to the influence of lumbar syndesmophytes and ankylosis on BMD measurements [22]. According to the EULAR taskforce, in patients with axSpA without syndesmophytes in the lumbar spine on conventional radiography, osteoporosis should be assessed using hip DXA and anteriorposterior spine DXA; however, in patients with syndesmophytes in the lumbar spine on conventional radiography, osteoporosis should be assessed using hip DXA supplemented with either spine DXA (lateral projection) or a QCT of the spine [10]. QCT information was not available for this CASTRO cohort, and many of these patients had syndesmophytes and structural damage at the lumbar level. In addition, we found that BMD in the lumbar spine was higher than that in the hip, which may be explained by the presence of new bone formation. For these reasons, we focused our analysis on hip DXA, since very few published studies have evaluated hip and femoral neck BMD in these patients.

Traditional risk factors for low BMD in the general population are female sex, increasing age, low Body Mass Index, menopause and the presence of chronic inflammatory diseases $[6,23]$. Interestingly, we found that a younger age was independently associated with low BMD in the total hip or femoral neck in patients with axSpA. Therefore, it seems that mainly younger axSpA patients (both males and females) are suffering from low $\mathrm{BMD}$, in contrast to primary osteoporosis, which is mostly found in older females. In the univariate analysis, low BMI was independently associated with the presence of osteopenia in the total hip and femoral neck. The reason for this association is that stress on the bone wall increases osteoblastic activity, and therefore, bone mass increases. Stress on the bone wall is mainly influenced by physical activity and other factors, such as muscle mass and fat tissue, due to the pull of gravity acting on the weight of soft tissues (fat, muscle). Thus, low BMI is associated with low BMD, less soft tissue and muscle weakness [24]. In addition, osteopenia was independently associated with a longer disease duration in our study. It 
has been reported that patients with long-standing axSpA have a higher risk of muscle loss because of reduced physical activity, immobilisation and inflammation $[25,26]$. Consistent with these reports, we found that both low BMD and osteopenia in either the total hip or femoral neck were associated with radiographic sacroiliitis, which may, in part, be a reflection of patients with a more severe disease and lower mobility, although no direct association was found with the UCOASMI. Inflammation imaged by an MRI, and systemic inflammation evaluated by C-reactive protein levels or the erythrocyte sedimentation rate have been proposed as factors associated with BMD loss [4]. However, we did not find an association with CRP or with ASDAS.

Due to the direct effect of inflammation on BMD, the use of NSAIDs and TNF blockers has been described as a protective factor against BMD loss [5,27]. The positive effect of NSAIDs may be explained by a direct effect on bone metabolism. NSAIDs might slow new bone formation in the spine and prevent heterotopic ossification by acting on biological factors such as bone morphogenetic proteins, metalloproteinases and PG receptor genes. In addition, NSAIDs may have an indirect effect through an increase in physical activity due to pain relief and the control of inflammation $[5,28]$. The effect of TNF-alpha blockers on increased BMD is attributed to its key role in bone resorption and formation. Osteoclast activity is enhanced by TNF-alpha, which also inhibits osteoclast apoptosis. In addition, excess TNF-alpha leads to the inhibition of the bone formation process $[5,29]$. Thus, the use of TNF-alpha blockers has demonstrated a similar effect on bone remodelling markers to that of antiresorptive drugs $[5,30]$. In fact, a metanalysis published by Haroon et al. demonstrated a significant improvement in BMD in the total hip after 1 and 2 years of follow-up in patients on TNF-alpha blockers [31]. In our study, we excluded patients under bDMARD therapy precisely to avoid bias in BMD measurements in patients on this type of drug. On the other hand, we found an inverse association between NSAID use and total hip BMD. This may be explained by the higher utilisation of NSAIDs in patients with a more severe disease, as has also been described in previous studies [32]. Interestingly, we found very low vitamin D levels in this study population, which may be explained by the fact that vitamin D levels were determined for the first time during this study visit. This makes us reflect on the necessity of systematically evaluating bone mineral metabolism in SpA patients.

Few studies have assessed the association between BMD and ASAS-HI, since this is a relatively recent metric that evaluates the health status in patients with SpA. Our results demonstrate that osteopenia or osteoporosis and low BMD in the hip and femoral neck are associated with poorer ASAS-HI scores, which may be driven by reduced function and mobility [33-35].

Our study has strengths and limitations. One limitation is the cross-sectional nature of the study, which prevents us from evaluating the causal association between osteopenia or osteoporosis and clinical factors. Another limitation is that this is a single-centre study. One strength of this study is that we removed patients on bDMARDs to avoid the effect of TNF-alpha blockers on BMD measurements. In addition, mobility was evaluated using an automated system to avoid intra-observer variability. Finally, X-rays (sacroiliitis and mSASSS) were scored by two rheumatologists to obtain reliable data.

\section{Conclusions}

In conclusion, our study showed that $36.0 \%$ of patients with axSpA had low BMD in the total hip or femoral neck. A younger age and radiographic sacroiliitis were the most important factors associated with this decrease in BMD. Prospective studies focused on hip $\mathrm{BMD}$ are needed to better understand bone metabolism in axSpA patients.

Author Contributions: Conceptualisation, P.F.-U., E.C.-E., A.E.-C. and C.L.-M.; formal analysis, L.B.-A., C.L.-M.; data collection, L.B.-A., L.L.-P., D.R.-V., M.d.C.Á.-A., M.Á.P.-L., A.S.-C., I.G.-G. and J.L.G.-C.; writing—original draft preparation, L.B.-A., C.L.-M.; writing—review and editing, all.; supervision, E.C.-E., A.E.-C., P.F.-U.; project administration, E.C.-E. All authors have read and agreed to the published version of the manuscript. 
Funding: This research received no external funding.

Institutional Review Board Statement: The study was conducted according to the guidelines of the Declaration of Helsinki and approved by the Institutional Review Board (or Ethics Committee) of Reina Sofia University Hospital (protocol code PI-0139-2017).

Informed Consent Statement: Informed consent was obtained from all the subjects involved in the study.

Data Availability Statement: Data are available upon reasonable request.

Acknowledgments: The authors would like to thank the patients who voluntarily participated in the CASTRO registry.

Conflicts of Interest: The authors declare no conflict of interest.

\section{References}

1. Dougados, M.; Baeten, D. Spondyloarthritis. Lancet 2011, 377, 2127-2137. [CrossRef]

2. Rudwaleit, M.; van der Heijde, D.; Landewé, R.; Listing, J.; Akkoc, N.; Brandt, J.; Braun, J.; Chou, C.T.; Collantes-Estevez, E.; Dougados, M.; et al. The Development of Assessment of Spondyloarthritis International Society Classification Criteria for Axial Spondyloarthritis (part II): Validation and Final Selection. Ann. Rheum. Dis. 2009, 68, 777-783. [CrossRef] [PubMed]

3. Moltó, A.; Etcheto, A.; van der Heijde, D.; Landewé, R.; Van den Bosch, F.; Molano, W.B.; Burgos-Vargas, R.; Cheung, P.P.; Collantes-Estevez, E.; Deodhar, A.; et al. Prevalence of Comorbidities and Evaluation of Their Screening in Spondyloarthritis: Results of the International Cross-Sectional ASAS-COMOSPA Study. Ann. Rheum. Dis. 2016, 75, 1016-1023. [CrossRef] [PubMed]

4. Briot, K.; Durnez, A.; Paternotte, S.; Miceli-Richard, C.; Dougados, M.; Roux, C. Bone Oedema on MRI is Highly Associated with Low Bone Mineral Density in Patients with Early Inflammatory Back Pain: Results from the DESIR Cohort. Ann. Rheum. Dis. 2013, 72, 1914-1919. [CrossRef]

5. Briot, K.; Etcheto, A.; Miceli-Richard, C.; Dougados, M.; Roux, C. Bone Loss in Patients with Early Inflammatory Back Pain Suggestive of Spondyloarthritis: Results from the Prospective DESIR Cohort. Rheumatology 2016, 55, 335-342. [CrossRef]

6. Malochet-Guinamand, S.; Pereira, B.; Tatar, Z.; Tournadre, A.; Moltó, A.; Dougados, M.; Soubrier, M. Prevalence and Risk Factors of Low Bone Mineral Density in Spondyloarthritis and Prevalence of Vertebral Fractures. BMC Musculoskel. Dis. 2017, 18, 357. [CrossRef]

7. Klingberg, E.; Lorentzon, M.; Mellström, D.; Geijer, M.; Göthlin, J.; Hilme, E.; Hedberg, M.; Carlsten, H.; Forsblad-d’Elia, H. Osteoporosis in Ankylosing Spondylitis-Prevalence, Risk Factors and Methods of Assessment. Arthritis Res. Ther. 2012, 14, R108. [CrossRef]

8. Kang, K.Y.; Goo, H.Y.; Park, S.H.; Hong, Y.S. Trabecular Bone Score as an Assessment Tool to Identify the Risk of Osteoporosis in Axial Spondyloarthritis: A Case-Control Study. Rheumatology 2018, 57, 462-469. [CrossRef]

9. Schett, G. Structural Bone Changes in Spondyloarthritis: Mechanisms, Clinical Impact and Therapeutic Considerations. Am. J. Med. Sci. 2011, 341, 269-271. [CrossRef]

10. Mandl, P.; Navarro-Compán, V.; Terslev, L.; Aegerter, P.; Van Der Heijde, D.; D’Agostino, M.A.; Baraliakos, X.; Pedersen, S.J.; Jurik, A.G.; Naredo, E.; et al. EULAR Recommendations for the Use of Imaging in the Diagnosis and Management of Spondyloarthritis in Clinical Practice. Ann. Rheum. Dis. 2015, 74, 1327. [CrossRef]

11. Van der Heijde, D.; Braun, J.; Deodhar, A.; Baraliakos, X.; Landewé, R.; Richards, H.B.; Porter, B.; Readie, A. Modified Stoke Ankylosing Spondylitis Spinal Score as an Outcome Measure to Assess the Impact of Treatment on Structural Progression in Ankylosing Spondylitis. Rheumatology 2019, 58, 388-400. [CrossRef] [PubMed]

12. Van der Linden, S.; Valkenburg, H.A.; Cats, A. Evaluation of Diagnostic Criteria for Ankylosing Spondylitis. A Proposal for Modification of the New York Criteria. Arthr. Rheum. 1984, 27, 361-368. [CrossRef]

13. Garrett, S.; Jenkinson, T.; Kennedy, L.G.; Whitelock, H.; Gaisford, P.; Calin, A. A New Approach to Defining Disease Status in Ankylosing Spondylitis: The Bath Ankylosing Spondylitis Disease Activity Index. J. Rheumatol. 1994, 21, $2286-2291$.

14. Calin, A.; Garrett, S.; Whitelock, H.; Kennedy, L.G.; O’hea, J.; Mallorie, P.; Jenkinson, T.A. New Approach to Defining Functional Ability in Ankylosing Spondylitis: The Development of the Bath Ankylosing Spondylitis Functional Index. J. Rheumatol. 1994, 21, 2281-2285. [PubMed]

15. WHO. Assessment of Fracture Risk and Its Application to Screening for Postmenopausal Osteoporosis; Report of a WHO Study Group, Technical Report Series; 843. WHO: Geneva, Switzerland, 1994; Volume 4, pp. 368-381.

16. Lukas, C.; Landewé, R.; Sieper, J.; Dougados, M.; Davis, J.; Braun, J.; Van der Linden, S.; Van der Heijde, D.; Assessment of SpondyloArthritis international Society. Development of an ASAS-Endorsed Disease Activity Score (ASDAS) in Patients with Ankylosing Spondylitis. Ann. Rheum. Dis. 2009, 68, 18-24. [CrossRef]

17. Garrido-Castro, J.L.; Escudero, A.; Medina-Carnicer, R.; Galisteo, A.M.; Gonzalez-Navas, C.; Carmona, L.; Collantes-Estevez, E. Validation of a New Objective Index to Measure Spinal Mobility: The University of Cordoba Ankylosing Spondylitis Metrology Index (UCOASMI). Rheumatol. Int. 2014, 34, 401-406. [CrossRef] [PubMed] 
18. Calvo-Gutierrez, J.; Garrido-Castro, J.L.; Gil-Cabezas, J.; Gonzalez-Navas, C.; Ugalde, P.F.; Carmona, L.; Collantes-Estevez, E. Is Spinal Mobility in Patients with Spondylitis Determined by Age, Structural Damage, and Inflammation? Arthr. Care Res. 2015, 67, 74-79. [CrossRef]

19. Garrido-Castro, J.L.; Curbelo, R.; Mazzucchelli, R.; Domínguez-González, M.E.; Gonzalez-Navas, C.; Robles, B.J.F.; Zarco, P.; Mulero, J.; Cea-Calvo, L.; Arteaga, M.J.; et al. High Reproducibility of an Automated Measurement of Mobility for Patients with Axial Spondyloarthritis. J. Rheumatol. 2018, 45, 1383-1388. [CrossRef]

20. Singh, H.J.; Nimarpreet, K.; Ashima, S.D.; Kumar, A.; Prakash, S. Study of Bone Mineral Density in Patients with Ankylosing Spondylitis. J. Clin. Diagn. Res. 2013, 7, 2832-2835. [CrossRef]

21. Van der Weijden, M.A.C.; Claushuis, T.A.M.; Nazari, T.; Lems, W.F.; Dijkmans, B.A.C.; Van Der Horst-Bruinsma, I.E. High Prevalence of Low Bone Mineral Density in Patients with 10 Years of Onset of Ankylosing Spondylitis: A Systematic Review. Clin. Rheumatol. 2012, 31, 1529-1535. [CrossRef]

22. Karberg, K.; Zochling, J.; Sieper, J.; Felsenberg, D.; Braun, J. Bone Loss is Detected More Frequently in Patients with Ankylosing Spondylitis with Syndesmophytes. J. Rheumatol. 2005, 32, 1290-1298.

23. De Laet, C.; Kanis, J.A.; Oden, A.; Johanson, H.; Johnell, O.; Delmas, P.; Eisman, J.A.; Kroger, H.; Fujiwara, S.; Garnero, P. Body Mass Index as a Predictor of Fracture Risk: A Meta-Analysis. Osteoporos. Int. 2005, 16, 1330-1338. [CrossRef]

24. Bing-Yan, X.; Huang, W.; Zhou, G.Q.; Hu, N.; Chen, H.; Chen, C. Body Mass Index and the Risk of Low Bone Mass-Related Fractures in Women Compared with Men: A PRISMA-Compliant Meta-Analysis of Prospective Cohort Studies. Medicine 2017, 96, e5290.

25. Ghozlani, I.; Ghazi, M.; Nouijai, A.; Mounach, A.; Rezqi, A.; Achemlal, L.; Bezza, A.; El Maghraoui, A. Prevalence and Risk Factors of Osteoporosis and Vertebral Fractures in Patients with Ankylosing Spondylitis. Bone 2009, 44, 772-776. [CrossRef] [PubMed]

26. Briot, K.; Roux, C. Inflammation, Bone Loss and Fracture Risk in Spondyloarthritis. RMD Open 2015, 1, e000052. [CrossRef]

27. Arends, S.; Spoorenberg, A.; Brouwer, E.; van der Veer, E. Clinical Studies on Bone-Related Outcome and the Effect of TNF- $\alpha$ Blocking Therapy in Ankylosing Spondylitis. Curr. Opin. Rheumatol. 2014, 26, 259-268. [CrossRef]

28. Randelli, F.; Pierannuzii, L.; Banci, L.; Ragone, V.; Aliprandi, A.; Buly, R. Heterotopic Ossifications after Arthroscopic Management of Femoroacetabular Impingement: The Role of NSAID Prophylaxis. J. Orthop. Traumatol. 2010, 1, 245-250. [CrossRef] [PubMed]

29. Glantsching, H.; Fisher, J.E.; Wesolowski, G.; Rodan, G.A.; Reszka, A.A. M-CSF, TNF-Alpha and RANK Ligand Promote Osteoclast Survival by Signaling through mTOR/S6 Kinase. Cell Death Differ. 2003, 10, 1165-1177. [CrossRef] [PubMed]

30. Briot, K.; Gossec, L.; Kolta, S.; Dougados, M.; Roux, C. Prospective Assessment of Body Weight, Body Composition, and Bone Density Changes in Patients with Spondyloarthritis Receiving Anti-Tumor Necrosis Factor-Alpha Treatment. J. Rheumatol. 2008, 35, 855-861. [PubMed]

31. Harron, N.N.; Sriganthan, J.; Al Ghanim, N.; Inman, R.D.; Cheung, A.M. Effect of TNF-Alpha Inhibitor Treatment on Bone Mineral Density in Patients with Ankylosing Spondylitis: A Systematic Review and Meta-Analysis. Semin. Arthr. Rheum. 2014, 44, 155-161. [CrossRef]

32. Prieto-Alhambra, D.; Munoz-Ortego, J.; De Vries, F.; Vosse, D.; Arden, N.K.; Bowness, P.; Cooper, C.; Diez-Perez, A.; Vestergaard, P. Ankylosing Spondylitis Confers Substantially Increased Risk of Clinical Spine Fractures: A Nationwide Case-Control Study. Osteoporos. Int. 2015, 26, 85-91. [CrossRef]

33. Gratacós, J.; Collado, A.; Pons, F.; Osaba, M.; Sanmarti, R.; Roque, M.; Larrosa, M.; Múñoz-Gómez, J. Significant Loss of Bone Mass in Patients with Early, Active Ankylosing Spondylitis: A Follow-Up Study. Arthr. Rheum. 1999, 42, 2319-2324. [CrossRef]

34. Toussirot, E.; Michel, F.; Wendling, D. Bone Density, Ultrasound Measurements and Body Composition in Early Ankylosing Spondylitis. Rheumatology 2001, 40, 882-888. [CrossRef] [PubMed]

35. Grazio, S.; Kusić, Z.; Cvijetić, S.; Grubišić, F.; Balenović, A.; Nemčić, T.; Matijević-Mikelić, V.; Punda, M.; Sieper, J. Relationship of Bone Mineral Density with Disease Activity and Functional Ability in Patients with Ankylosing Spondylitis: A Cross-Sectional Study. Rheumatol. Int. 2012, 32, 2801-2808. [CrossRef] [PubMed] 